6

\title{
Optimal Management of Complicated Infections in the Pediatric Patient: The Role and Utility of Ceftazidime/Avibactam
}

This article was published in the following Dove Press journal:

Infection and Drug Resistance

\section{Matteo Bassetti ${ }^{1,2}$ \\ Maddalena Peghin (D) \\ Alessio Mesini $\left(\mathbb{D}^{3}\right.$ \\ Elio Castagnola $\mathbb{D}^{3}$}

'Infectious Diseases Clinic, Department of Medicine University of Udine and Azienda Sanitaria Universitaria Integrata, Udine, Italy; ${ }^{2}$ Department of Health Sciences, University of Genoa, Genoa, Italy; ${ }^{3}$ Division of Infectious Diseases, IRCCS Istituto Giannina Gaslini, Genoa, Italy
Correspondence: Matteo Bassetti Clinica Malattie Infettive, Azienda Ospedaliera Universitaria Santa Maria Della Misericordia, Piazzale Santa Maria Della Misericordia 15, Udine 33100, Italy Tel +390432559355

Fax +390432559360

Email matteo.bassetti@asuiud.sanita.fvg.it

\begin{abstract}
Antimicrobial resistance poses a substantial threat to global public health. The pursuit of new antibiotics has decreased and very few options have been investigated for the treatment of complicated multidrug-resistant Gram-negative (MDR-GN) infections in adult population and even less in pediatric patients. Ceftazidime-avibactam (CAZ-AVI) is novel cephalosporin/ $\beta$-lactamase inhibitor (BL-BLI) combination with broad antibacterial spectrum. The aim of this review is to describe the current and future role CAZ-AVI in the pediatric population with suspected or confirmed MDR-GN infections.
\end{abstract}

Keywords: pediatric, infections, multidrug-resistant Gram-negative, ceftazidime/avibactam

\section{Introduction}

Over the last years, the prevalence of multidrug-resistant Gram-negative (MDRGN) pathogens has increased worldwide, both in adults and in children. ${ }^{1}$ Antimicrobial resistance poses a substantial threat to global public health concern, since it decreases the probability of effectively treating an infection and increases risk of morbidity and mortality. Nevertheless, the pursuit of new antibiotics has decreased for years and very few options have been investigated for the treatment of complicated MDR-GN infections in adult population and even less in pediatric patients. ${ }^{2}$ More recently, new molecules have been proposed for use in clinical practice, such as ceftazidime-avibactam (CAZ-AVI), a novel cephalosporin/ $\beta$ lactamase inhibitor (BL-BLI) combination with a broad antibacterial spectrum.

CAZ-AVI was first approved in adult population by Food and Drug Administration (FDA) and European Medicines Agency (EMA) in 2015 for adults complicated urinary tract infections (cUTI), complicated intra-abdominal infections (cIAI) and, in February 2018, it was approved for the treatment of hospital-acquired pneumonia (HAP), and ventilator-associated pneumonia (VAP). ${ }^{3}$ Furthermore, CAZ-AVI received approval by EMA for infections due to aerobic Gram-negative organisms in adult patients with limited treatment options. In March 2019, FDA has expanded the approval of CAZ-AVI to include pediatric patients aged $\geq 3$ months for the treatment of cIAI, used in combination with metronidazole, and for cUTI, including pyelonephritis. Safety and effectiveness have not been established in pediatric patients with HAP/VAP (Table 1).

The aim of this review is to describe the current and future role CAZ-AVI in pediatric population with suspected or confirmed MDR-GN infections. 
Table I Indication and Usage of CAZ-AVI in Adult and Pediatric Population

\begin{tabular}{|l|l|}
\hline $\begin{array}{l}\text { Adult Population (18 Years } \\
\text { and Older) }\end{array}$ & $\begin{array}{l}\text { Pediatric Population } \\
\text { (3 Months and Older) }\end{array}$ \\
\hline - clAl, used in combination with & - clAl, used in combination \\
metronidazole & with metronidazole \\
- cUTI, including pyelonephritis & - cUTI, including pyelonephritis \\
- HAP, VAP & \\
- Infections due to aerobic Gram- \\
negative organisms in adult patients \\
with limited treatment options.
\end{tabular}

Abbreviations: cIAl, complicated intra-abdominal infections; cUTI, complicated urinary tract infections; HAP, hospital-acquired pneumonia; VAP, ventilatorassociated pneumonia.

\section{Epidemiology and Risk Factors for MDR-GN in Pediatric Population}

The number of pediatric patients with severe bacterial infections due to MDR bacteria is increasing and their morbidity and mortality are considerable. ${ }^{1,4,5}$ Understanding the epidemiology and the drug resistance patterns of infections in children is crucial to provide appropriate antimicrobial prescription and to guide antimicrobial stewardship programs.

Previous studies have demonstrated that GN infections account for $30-55 \%$ of all bloodstream infections (BSIs) detected in children depending on age stratification, type of ward, comorbidity and geographical setting. The most frequent isolated microorganism is E. coli and K. pneumoniae followed by $P$. aeruginosa. ${ }^{6}$ Hospital data from developing countries suggest that pathogens causing neonatal infections (in the first 28 days of life) and in early-onset (likely maternally-acquired neonatal infections) are frequently resistant to first line regimen with ampicillin plus gentamicin. ${ }^{7}$

The most important emerging MDR-GN pathogens in children are extended-spectrum $\beta$-lactamases (ESBL), carbapenem-resistant Enterobacteriaceae (CRE), MDR and carbapenem-resistant (CR) P. aeruginosa.

Despite the increased global attention to MDR-GN, little research has been conducted on these infections in children, the few available data suggest that MDR-GN epidemiology, risk factors, and outcomes are comparable with those observed in adults. ${ }^{8}$ Nosocomial outbreaks have been reported in neonatal and pediatric intensive care units and the geographical distribution was generally consistent with adults patients one. ${ }^{8}$

Bacterial surveillance, strategies for implementing effective infection-prevention, and antimicrobial stewardship programs specifically for children are needed.

\section{ESBL Infections}

The isolation of third generation cephalosporin-resistant and ESBL-producing Enterobacteriaceae (ESBL-PE) is becoming more common across pediatric patients, both in the community and in health care settings. ${ }^{9}$ These findings are consistent with previous data in adults, which also report an upward trend in EBSL in inpatient and outpatient settings. SENTRY Antimicrobial Surveillance Program in Europe, North and South America (1997-2002) signaled that among $<1$ and $1 \pm 12$ years old children, the prevalence of ESBL-producing isolates among Klebsiella spp. bloodstream pathogens was $41.7 \%$ and $31.3 \%$, respectively. ${ }^{10}$ A large national database of antimicrobial susceptibility in the United States has found that the prevalence of third generation cephalosporin-resistant and ESBL phenotypes increased, respectively, from $1.39 \%$ and $0.28 \%$ in $1999-2001$ to $3 \%$ and $0.92 \%$ in $2010-2011 .^{11}$

A systematic review and meta-analysis reporting the prevalence of ESBL-PE among confirmed BSIs in 3381 pediatric patients from 1996 to 2013 has found that the prevalence of ESBL-PE was $9 \%$ with an annual increase of $3.2 \%(\mathrm{P}=0.04)$, with higher prevalence rates among neonates (11\%) compared to children older than 28 days $(5 \%)$. The pooled prevalence was higher in Africa (15\%), South America (12\%), India (11\%) and the rest of Asia (7\%), compared to Europe (4\%) and Oceania (0\%). Importantly, these infections appear to be more common among neonates while the mortality rate among neonates with BSI due to ESBL-PE was 36\%, significantly higher compared to those infected with other pathogens $(18 \%$, $\mathrm{p}=0.01){ }^{12}$

Clinical risk factors for ESBL colonization and infection for children, besides prematurity and low weight at birth, are quite similar to those described in adults, such as gender, country of birth, travel outside metropolitan area, immunosuppression, underlying chronic disease, urinary tract disease, previous hospitalization, local outbreaks, prolonged length of stay, known ESBL carriage, prior antibiotic use, and indwelling devices. ${ }^{9,13}$

After the development of an algorithm in adult population, ${ }^{14}$ a decision tree illustrating the risk of antimicrobial resistance among children with GNB BSI based on individual patient risk factors has been recently proposed for pediatric population, but it needs to be validated more widely before incorporation into clinical practice. ${ }^{15}$ 


\section{CRE Infections}

Despite global attention to CRE, limited data have been published on the epidemiology of these infections in children, ${ }^{16} \mathrm{CRE}$ in pediatrics are less frequently described compared to ESBL. However, the growing number of infections reports along with an increasingly medically complex pediatric population suggest that CRE could emerge as a significant nosocomial pathogen in pediatric centers over the coming years. ${ }^{17} \mathrm{~A}$ large national database of antimicrobial susceptibility in the United States found that the frequency of carbapenem resistance increased from $0 \%$ in $1999-2000$, to $0.47 \%$ in $2010-2011$ among Enterobacteriaceae in children. ${ }^{18}$ The frequency of meropenem-resistant $K$. pneumoniae and $E$. coli pediatric isolates has been reported as approximately $4 \%$ and $<1 \%$ worldwide, respectively. ${ }^{19}$

Children with CRE infection tend to be very young and critically ill, and potential risk factors include: age, travel from endemic regions, chronic comorbidity, presence of indwelling devices (including mechanical ventilation), history of surgery, prior colonization, immunosuppressive agents exposure, frequent or prolonged hospitalizations and previous antibiotic use. ${ }^{17,20}$ Other identified risk factors include intensive care unit stay, solid organ transplant, renal failure, bedbound status, pediatric long-term care facilities. ${ }^{16}$ Mortality rates in children with CRE have been reported as very variable, but neonates seem to be the group with the highest risk. ${ }^{21}$

\section{MDR and CR $P$. aeruginosa Infections}

Infections due to $P$ aeruginosa in children are reported most often in association with pulmonary disease in patients with cystic fibrosis. ${ }^{22}$

A recent national surveillance network assessed the epidemiology of 300 P. aeruginosa isolates from 77,349 children without cystic fibrosis (inpatient, outpatient and long-term care facilities) and analyzed trends in antibiotic resistance.

From 1999 to 2012, the prevalence of MDR isolates increased significantly from $15.4 \%$ to $26 \%$, while CR isolates rose significantly from $9.4 \%$ to $20 \%$. After adjusting by year, patient and isolate characteristics, the prevalence of MDR and CR P. aeruginosa was higher among children aged 13-17 years, in the West North Central region of the US and in respiratory specimens. The highest prevalence of CR P. aeruginosa was among patients in
ICU, while for MDR prevalence was in children in longterm care facilities. ${ }^{23}$

\section{CAZ-AVI Mechanism of Action and Spectrum of Action}

CAZ-AVI is a recently marketed novel agent containing the third-generation cephalosporin, ceftazidime, and avibactam, a newly developed BL-BLI. Ceftazidime inhibits peptidoglycan synthesis by binding to a variety penicillinbinding proteins (PBP), including the PBP3 of Gramnegative bacteria, including $P$. aeruginosa, resulting in cell wall instability and cell death. Avibactam demonstrates excellent in vitro activity against a wide range of bacterial beta-lactamases, including Ambler class A [including ESBL and Klebsiella pneumoniae carbapenemase (KPC)], C (AmpC), and some class D serine betalactamases [eg, oxacillinase (OXA) 48] (Table 2). ${ }^{24}$

In-vitro studies showed that the combination of CAZAVI is highly effective also against d P. aeruginosa and demonstrated activity against some MDR and CR P. aeruginosa isolates. ${ }^{25,26}$ Avibactam has a limited activity against $A$. baumannii and other anaerobic Gramnegative rods ${ }^{27}$ (Tables 1 and 2).

Notably, avibactam is not able to inhibit strains producing metallo- $\beta$-lactamases (MBL-Class $\mathrm{B}$ ), such as the New Delhi metallo- $\beta$-lactamase (NDM), Verona integronencoded metallo- $\beta$-lactamase (VIM) and Imipenmase (IMP), as well as many of the Class D enzymes, including Acinetobacter OXA carbapenemases. ${ }^{28}$ However, in vitro studies suggested a synergistic effect of aztreonam combined with CAZ-AVI for MDR Enterobacteriaceae MBL producers, but this combination unfortunately is not yet commercialized. ${ }^{29,30}$ Interestingly, CAZ-AVI has shown highly bactericidal activity in vitro against Mycobacterium avium complex and Mycobacterium tuberculosis, including MDR strains ${ }^{31,32}$ (Tables 2 and 3).

During treatment of carbapenem-resistant Klebsiella pneumoniae infection, the emergence of CAZ-AVI resistance, due to KPC-2- and KPC-3-producing isolates, was noted in approximately $10 \%$ of cases. Noteworthy, some of the mutations that confer resistance to ceftazidime-avibactam can reduce the carbapenemase activity of KPC-3, resulting in lower carbapenem MICs and restoring the susceptibility of these isolates to carbapenems, however, this is generally not sustainable. ${ }^{33}$ 
Table 2 Classification of Most Frequent Extended-Spectrum b-Lactamases and Carpapenemase

\begin{tabular}{|c|c|c|c|}
\hline $\begin{array}{l}\text { Molecular } \\
\text { Class }\end{array}$ & Enzymes & $\begin{array}{l}\text { Relevant } \\
\text { Organisms }\end{array}$ & Substrates of Hydrolysis \\
\hline A & $\begin{array}{l}\text { ESBL (TEM, SHV, CTX-M, } \\
\text { others) }\end{array}$ & $\begin{array}{l}\text { - E. coli } \\
\text { - Klebsiella spp. } \\
\text { - Proteus mirabilis }\end{array}$ & Penicillins, cephalosporins (except cefamycins), aztreonam. \\
\hline A & KPC & $\begin{array}{l}\text { - E. coli } \\
\text { - K. pneumoniae } \\
\text { - K. oxytoca } \\
\text { - Serratia marcescens } \\
\text { - Enterobacter spp. } \\
\text { - Citrobacter freundii }\end{array}$ & Penicillins, cephalosporins, aztreonam, carbapenems. \\
\hline B & $\begin{array}{l}\text { MBLs (VIM, IMP, NDM, } \\
\text { others) }\end{array}$ & $\begin{array}{l}\text { - E. coli } \\
\text { - K. pneumoniae } \\
\text { - K. oxytoca } \\
\text { - Serratia marcescens } \\
\text { - Enterobacter spp. } \\
\text { - Citrobacter freundii }\end{array}$ & $\begin{array}{l}\text { Penicillins, cephalosporins and carbapenems. Monobactams are } \\
\text { susceptible. }\end{array}$ \\
\hline $\mathrm{C}$ & AmpC & $\begin{array}{l}\text { - } \text { K. pneumoniae } \\
\text { - E. coli } \\
\text { - Enterobacter spp. } \\
\text { - Salmonella } \\
\text { enteritidis } \\
\text { - C. freundii } \\
\text { - S. marcescens }\end{array}$ & Cephamycins, 3rd generation cephalosporins \\
\hline $\mathrm{D}$ & $\begin{array}{l}\text { OXA (OXA-48, OXA-23, } \\
\text { others) }\end{array}$ & $\begin{array}{l}\text { - } \text { Acinetobacter } \\
\text { baumannii } \\
\text { - } \text { P. aeruginosa } \\
\text { - } \text { E. coli } \\
\text { - } \text { K. pneumoniae } \\
\text { - } \text { P. mirabilis } \\
\text { - } \text { C. freundii }\end{array}$ & Penicillin, aztreonam and carbapenems \\
\hline
\end{tabular}

Abbreviations: ESBL, extended-spectrum b-lactamases; IMP, imipenmase metallo-beta-lactamase; KPC, Klebsiella pneumoniae carbapenemase; MBLs, metallo- $\beta$-lactamases; NDM, New Delhi metallo-beta-lactamase; OXA-48, oxacillinase-48; OXA-23, oxacillinase-23; VIM, Verona integron-encoded metallo-beta-lactamase.

CAZ-AVI Pharmacokinetics/ Pharmacodynamics, Safety, Tolerability and Clinical Effectiveness in the Pediatric Population

Limited reports have been available on CAZ-AVI use in infants, children, and adolescents prior to the FDA approval for pediatric patients. ${ }^{30,34}$

Search for clinical trials on ceftazidime-avibactam in patients ageing $<18$ years was performed in European ${ }^{35}$ and USA database. ${ }^{36}$ A total of 6 clinical trials were retrieved, but two were included in both registries. Only one clinical trial was complete and results were published $^{37,38}$ in a peer-reviewed journal. ${ }^{39}$ This was a PK/ PD and safety clinical trial on a single dose CAZ-AVI, and it involved a total of 32 patients, 8 (25\%) aging 28 days-23 months. Patients received a single 2 -h intravenous infusion of ceftazidime-avibactam with different dosages based on age and/or body weight. Mean plasma concentration-time curves, geometric mean maximum concentration (Cmax), and area under the concentration-time curve from time zero to infinity were similar across all cohorts for both drugs and comparable between each of the 4 age groups and similar to those previously observed in adults. Overall, proportion of patients experiencing mild to moderate adverse events was about 19\%. Another single-dose PK/PD and tolerability study is planned in children from 3 months to less than 18 years of age with nosocomial pneumonia is planned but not still recruiting patients. ${ }^{40}$ Age cohorts identified are the same 
Table 3 Spectrum of Activity of Ceftadizime/Avibactam

\begin{tabular}{|l|l|}
\hline ACTIVE in vitro & NOT ACTIVE in vitro \\
\hline - Aeromonas & - MRSA \\
- Arcanobacter & - Anaerobes \\
- B. cepacia & - Enterococcus sPP. \\
- Capnocytophaga & - Stenotrophomonas \\
- Citrobacter freundii +Citrobacter koseri & maltophilia \\
- Enterobacter aerogenes + Enterobacter & - Acinetobacter sPP \\
cloacae & (limited activity) \\
- Escherichia coli & \\
- Hemophilus influenzae & \\
- Kingella spP & \\
- Leptospira spP & \\
- Klebsiella oxytoca + Klebsiella pneumoniae & \\
- Mycobacterium avium & \\
- Mycobacterium tuberculosis & \\
- Moraxella catarrhalis & \\
- Morganella spp. & \\
- Neisseria meningitides & \\
- Propionibacterium acnes \\
- Pseudomonas aeruginosa \\
- Proteus mirabilis + Proteus vulgaris \\
- Peptostreptococci \\
- Providencia spp.
\end{tabular}

Abbreviations: CRE, carbapenem-resistant Enterobacteriaceae; ESBL, extendedspectrum beta-lactamase; IMP, imipenmase; MBLs, metallo- $\beta$-lactamases; MDRGN, multidrug-resistant gram-negatives; MRSA, methicillin-resistant Staphylococcus aureus; NDM, New Delhi metallo- $\beta$-lactamase; VIM, Verona integron-encoded metallo$\beta$-lactamase ${ }^{\circ}$ including MDR strains; ${ }^{*}$, in vitro sensitive strains.

of those of PK/PD study already published, but no data on dosages are reported. Finally, 2 clinical studies evaluated CAZ-AVI in urinary tract infections ${ }^{41,42}$ (number of patients enrolled 97, 38 [39\%] aging 28 days-23 months) and intraabdominal infections ${ }^{43}$ (number of patients enrolled 83, 1 [1.2\%] aging 28 days-23 months). Patients' stratifications and dosages were the same used in the other studies. Data from the study in cUTI have been recently published ${ }^{44}$ and showed a safety profile consistent with that on adults and of ceftazidime alone, and effectiveness in children with urinary tract infections due to Gram-negative pathogens. In addition, CAZ-AVI plus metronidazole has shown to be well tolerated, with a safety profile similar to ceftazidime alone, and appeared effective in pediatric patients with cIAI due to Gram-negative pathogens, including ceftazidime-nonsusceptible strains. ${ }^{45}$ Some further data are available from single case reports or small series. ${ }^{34,46,47}$

Caution should exercised if CAZ-AVI is to be administered to a penicillin or other beta-lactam allergic patient. The most common adverse reactions $(\geq 3 \%)$ in pediatric patients were vomiting, diarrhea, rash, and infusion site phlebitis. The risk of adverse events includes $C$. difficileassociated diarrhea, which has been reported for nearly all systemic antibacterial drugs, including CAZ-AVI, fungal superinfections and central nervous system events (seizure and other CNS reactions), primarily described in the setting of renal impairment. ${ }^{48}$ Monitoring Creatinine Clearance $(\mathrm{CrCl})$ at least daily in adult and pediatric patients with changing renal function and adjust the dose of CAZ-AVI accordingly is recommended.

\section{CAZ-AVI Monotherapy and Combination Therapy in Pediatric Population}

Treatment options with ceftazidime-avibactam and combination therapy for MDR-GN infections in pediatrics are summarized in Table 4, according to in vitro activity or case series in adults. Real life use of CAZ-AVI is encouraging, in terms of safety, clinical response. The biggest concern is the emergence of resistance. According to clinical experience, continuous (over 8 hours) or prolonged infusion (over 2-3 hours) is recommended in order to maximize the bactericidal effect of intravenous betalactam antibiotics. ${ }^{44,45,49}$ Concern for resistance and the need of increasing the bactericidal effect of the treatment during severe infections, probably justifies the combination of CAZ-AVI with other antibiotics (Table 3). ${ }^{50-52}$

In vitro potential advantages were found against Pseudomonas spp combining CAZ-AVI with rifampin, fosfomycin or colistin, ${ }^{53-55}$ and synergistic activity was observed with carbapenems as meropenem or imipenem against Klebsiella pneumoniae $\mathrm{KPC}^{56}$ and Serratia marcescens. ${ }^{57}$

CAZ-AVI plus aztreonam combination has been studied in vitro and in vivo. ${ }^{58,59}$ Aztreonam is a monobactam with low grade of cross-hypersensitivity reactions in 
Table 4 Treatment Options with Ceftazidime-Avibactam and Combo Therapy for MDR-GN Infections. Dose Adjustment Is Recommended Depending on Renal Function and Antimicrobial Susceptibility Tests

\begin{tabular}{|c|c|c|}
\hline Drug & Dosage & Reference \\
\hline $\begin{array}{l}\text { Ceftazidime/ } \\
\text { avibactam }\end{array}$ & $\begin{array}{l}\text { According to weight and age-Weight }<40 \mathrm{~kg} \geq 6 \text { months to }<18 \text { year: } 50+12.5 \mathrm{mg} / \mathrm{kg} \text { every } 8 \text { hours-Weight } \\
>40 \mathrm{~kg} \geq 6 \text { years: } 2000+500 \mathrm{mg} / \mathrm{kg} \text { every } 8 \text { hoursAccording to age } \geq 3 \text { to }<6 \text { months: } 40+10 \mathrm{mg} / \mathrm{kg} \text { every } 8 \text { hours } \\
\text { Observations: El (over } 3 \mathrm{~h} \text { ) every } 8 \text { hours is recommended }\end{array}$ & [44] \\
\hline Aztreonam & $90-120 \mathrm{mg} / \mathrm{kg} /$ day divided in 3 doses $/ n$ Cystic fibrosis 200 to $300 \mathrm{mg} / \mathrm{kg} /$ day divided in 4 doses & {$[99,100]$} \\
\hline Meropenem & $\begin{array}{l}60 \mathrm{mg} / \mathrm{kg} / \text { day divided in } 3 \text { doses } \mathrm{ln} \text { Cystic fibrosis or onco/hematological patients } 120 \mathrm{mg} / \mathrm{kg} / \text { day divided in } 3 \\
\text { dosesObservations: } \mathrm{Cl} \text { every } 6 \mathrm{~h} \text { in } 6 \text { hours or El every } 8 \text { hours over } 3-6 \text { is recommended }\end{array}$ & {$[101]$} \\
\hline Fosfomycin & $\begin{array}{l}\text { According to weight and age-Premature neonates, corrected gestational age }<40 \text { weeks: } 100 \mathrm{mg} / \mathrm{kg} \text { divided in } 2 \\
\text { doses-Neonates, corrected gestational age } * 40-44 \text { weeks: } 200 \mathrm{mg} / \mathrm{kg} \text { in } 3 \text { divided doses*I to } 12 \text { months (up to } \\
10 \mathrm{~kg} \text { ): } 200-300 \mathrm{mg} / \mathrm{kg} \text { in } 3 \text { divided doses*I to } 12 \text { years }(10 \text { to } 40 \mathrm{~kg} \text { ): } 200-400 \mathrm{mg} / \mathrm{kg} \text { in } 3 \text { to } 4 \text { divided } \\
\text { dosesObservations: Always in combination therapy. Contains high sodium concentrations. Caution is } \\
\text { recommended in patients with liver cirrhosis or heart failure }\end{array}$ & {$[62,64]$} \\
\hline Colistin & $\begin{array}{l}\text { Caution required due to very limited safety data-Usual adult dose is: } 9.000 .000 \mathrm{IU} \text { as loading dose and } \\
\text { then } 4.500 .00 \mathrm{IU} \text { every } \mathrm{I} 2 \text { hours } \\
\text { Possible dosage suggested based on available data: } 200.000 \mathrm{IU} / \mathrm{kg} \text { loading dose and then } 100.000 \text { every } \mathrm{I} 2 \text { hours } \\
\text { Observations: High doses are associated with renal toxicity }\end{array}$ & {$[69-75,78]$} \\
\hline Tigecycline & According to age 8 to 11 years: $1.2 \mathrm{mg} / \mathrm{kg}$ (max $50 \mathrm{mg}$ ) every 12 hours 12 to 17 years: $50 \mathrm{mg}$ every 12 hour & {$[77,102]$} \\
\hline Amikacin & I5-20 mg/kg/day single doseObservations: High doses are associated with renal toxicity & {$[83,101]$} \\
\hline Gentamicin & $7 \mathrm{mg} / \mathrm{kg} /$ day single doseObservations: High doses are associated with renal toxicity & {$[101]$} \\
\hline Rifampicin & $20 \mathrm{mg} / \mathrm{kg} /$ day single doseObservations: Always in combination therapy & {$[61,78,85]$} \\
\hline
\end{tabular}

Notes: The loading dose should be administered in all patients including those with renal dysfunction. Antimicrobial susceptibility test: Colistin: MIC $\leq 2$ mg/L continue colistin; $\mathrm{MIC}>2 \mathrm{mg} / \mathrm{L}$ consider alternative in vitro active antimicrobial. Tigecycline: $\mathrm{MIC} \leq \mathrm{I} \mathrm{mg} / \mathrm{L}$ consider tigecycline; $\mathrm{MIC}>\mathrm{I} \mathrm{mg} / \mathrm{L}$ consider alternative in vitro active antimicrobial. Fosfomycin: MIC $\leq 32 \mathrm{mg} / \mathrm{L}$ consider fosfomycin; MIC $>32 \mathrm{mg} / \mathrm{L}$ consider alternative in vitro active antimicrobial. Aminoglycoside: MIC $\leq 2 \mathrm{mg} / \mathrm{L}$ for gentamicin/ tobramycin or $\leq 4 \mathrm{mg} / \mathrm{L}$ for amikacin consider aminoglycoside; MIC $>2$ for gentamicin/tobramycin or $>4 \mathrm{mg} / \mathrm{L}$ for amikacin consider alternative in vitro active antimicrobial. Abbreviations: $\mathrm{Cl}$, continuous infusion; El, extended infusion; h, hours.

patients allergic to other beta-lactams. The combination could provide coverage against MBLs that are not neutralized by avibactam. Unfortunately, recent data on aztreonam mostly regard its administration by in inhalation (aztreonam lysine in cystic fibrosis) and no clinical experience is available nowadays in pediatrics (Table 4). ${ }^{50,60-63}$

Fosfomycin dose varies widely according to countries, but its best administration is probably based on weight and age, using correct gestational age in pre-term neonates, up to the maximum dose of $400 \mathrm{mg} / \mathrm{kg}$ in 4 divided doses in life-threatening infection. The compound contains a high concentrations of sodium that can lead to ion balance alteration with the possibility of severe adverse events, especially in patients with heart diseases ${ }^{64}$ and/or cirrhosis. ${ }^{65}$ In neonates there is a reduced ability in excreting large amount of $\mathrm{Na}^{+}$, so they could be at high risk of developing high sodium plasma concentrations following fosfomycin infusion, leading to chronic lung disease. ${ }^{64,66}$ Considering the risk of selecting for resistant strains, fosfomycin should be administered in combination with other drugs especially for MDR-GN (Table 4). ${ }^{67}$

Colistin is frequently used for treatment of infections due to MDR-GN. ${ }^{68}$ Unfortunately, data on safety and dosage in pediatrics are very limited and still not well defined. This drug seems to be well tolerated even at high dosage and renal adverse events are reversible after drug interruption. ${ }^{69-73}$ Plasma concentrations should be monitored to improve its effectiveness and reduce toxicity, but this practice can be challenging due to instrument variability (Table 4). ${ }^{69,74,75}$

The use of tigecycline in children aged $>8$ years is approved by EMA, when no other options are available, ${ }^{76}$ for a maximum of $50 \mathrm{mg} /$ dose, without a loading dose. ${ }^{77}$ Data available from adults indicate that a higher dosage could be needed ${ }^{78}$ in order to improve plasma concentration and drug effectiveness. ${ }^{79}$ It is not known if higher doses should be used also in pediatrics. Availability of therapeutic drug monitoring (TDM) could 
be useful to solve this question. Tigecycline is usually well tolerated, ${ }^{76}$ but adverse events are reported, especially nausea and vomiting. ${ }^{80}$ Substantially, there are no data for patient aged $<8$ years (Table 4 ).

Aminoglycosides are concentration-depending bactericidal drug usually administered as part of a combination therapy with notorious oto-and nephro-toxicity ${ }^{81}$ that is reduced by a once-daily high dose schedule. ${ }^{82,83}$ This schedule of administration can be considered as a standard also in pediatrics. ${ }^{84}$

As for many other molecules, there is a lack of recent data for rifampicin use in pediatric population for nonmycobacterial infection. A single daily-dose is generally suggested, but it must be used in combination with other drugs in order to limit the onset of resistant strains (Table 4). ${ }^{61,85,86}$

Finally, also meropenem can show higher success rate against strains with higher MIC values in children, compared to standard dosage, when administered as extended or continuous infusion, ${ }^{87-90}$ in order to provide a pharmacodynamic exposures of $40 \% \mathrm{~T}>\mathrm{MIC},{ }^{91}$ or when it is administered at double dosage as in cystic fibrosis. ${ }^{92}$ Data in adults in intensive care unit have shown the risk of central nervous system toxicity with high plasma concentrations of meropenem, ${ }^{93}$ but this observation has not been confirmed in pediatrics. ${ }^{94}$ In this case, the possibility to perform therapeutic drug monitoring of at least some of the drugs indicated for combination therapy ${ }^{95-98}$ could further improve effectiveness and reduce the toxicity of these treatments (Table 4).

\section{Conclusions and Future Prospective}

In conclusion, CRE may emerge as a significant nosocomial pathogen over the coming years in the pediatric population. CAZ-AVI stands out as one of the most important additions in our armamentarium, as the first marketed fixed combination with activity against KPC and OXA producers. In addition, ceftazidime-avibactam can be used in combination with aztreonam to treat infections caused by a MBL-producing organism. Real life use of CAZ-AVI is encouraging, in terms of safety, clinical response, and survival both in adult and pediatric population. The biggest concern is the emergence of resistance in KPC-producing organisms and an irrational use of this antibiotic should be avoided. In our opinion and based on previous data on CRE infections from observational studies, we believe that $\mathrm{PK} / \mathrm{PD}$ optimisation with CAZ-AVI extended infusion and combination therapy (with an aminoglycoside, TMP/SMX, fosfomycin, tigecycline, colistin) may be considered as a potential option to avoid the emergence of resistances. Companion drugs of CAZ-AVI can be selected based on susceptibility tests and infection site. The broad spectrum covering also ESBL-PE and significant proportions of $P$. aeruginosa, makes CAZ-AVI an interesting treatment option also for empiric regimens in patients with risk factors for MDR-GN infections and as a target carbapenem saving strategy. High-quality clinical trials on new and old antibiotics are needed to allow the definition of the currently best available empirical and target treatments for MDR-GN infections in the pediatric population.

\section{Disclosure}

Dr Matteo Bassetti reports grants, personal fees from Shionogi, grants, personal fees from Pfizer, grants, personal fees from MSD, personal fees from Paratek, personal fees from Astellas, grants, personal fees from Menarini, personal fees from Angelini, grants, personal fees from Tetraphase, grants, personal fees from Gilead, outside the submitted work. Dr Maddalena Peghin reports grants from Pfizer, grants from Thermofisher, outside the submitted work. The authors report no other conflicts of interest in this work.

\section{References}

1. Weiner LM, Webb AK, Limbago B, et al. Antimicrobial-resistant pathogens associated with healthcare-associated infections: summary of data reported to the national healthcare safety network at the centers for disease control and prevention, 2011-2014. Infect Control Hosp Epidemiol. 2016;37(11):1288-1301. doi:10.1017/ice.2016.174

2. Bassetti M, Russo A, Carnelutti A, La Rosa A, Righi E. Antimicrobial resistance and treatment: an unmet clinical safety need. Expert Opin Drug Saf. 2018;17(7):669-680. doi:10.1080/14740338.2018.1488962

3. Bassetti M, Peghin M, Vena A, Giacobbe DR. Treatment of infections due to MDR gram-negative bacteria. Front Med. 2019;6:74. doi:10.3389/fmed.2019.00074

4. Larru B, Gong W, Vendetti N, et al. Bloodstream infections in hospitalized children: epidemiology and antimicrobial susceptibilities. Pediatr Infect Dis J. 2016;35(5):507-510. doi:10.1097/INF.0000000000001057

5. Chiotos K, Tamma PD, Flett KB, et al. Increased 30-day mortality associated with carbapenem-resistant enterobacteriaceae in children. Open Forum Infect Dis. 2018;5(10):ofy222. doi:10.1093/ofid/ofy222

6. Ivady B, Kenesei E, Toth-Heyn P, et al. Factors influencing antimicrobial resistance and outcome of Gram-negative bloodstream infections in children. Infection. 2016;44(3):309-321. doi:10.1007/s15010-015-0857-8

7. Laxminarayan R, Matsoso P, Pant S, et al. Access to effective antimicrobials: a worldwide challenge. Lancet. 2016;387(10014):168-175. doi:10.1016/S0140-6736(15)00474-2

8. Folgori L, Bielicki J. Future challenges in pediatric and neonatal sepsis: emerging pathogens and antimicrobial resistance. $J$ Pediatr Intensive Care. 2019;8(1):17-24. doi:10.1055/s-0038-1677535

9. Toubiana J, Timsit S, Ferroni A, et al. Community-onset extended-spectrum beta-lactamase-producing enterobacteriaceae invasive infections in children in a university hospital in France. Medicine. 2016;95(12):e3163. doi:10.1097/MD.0000000000003163 
10. Biedenbach DJ, Moet GJ, Jones RN. Occurrence and antimicrobial resistance pattern comparisons among bloodstream infection isolates from the SENTRY Antimicrobial Surveillance Program (1997-2002). Diagn Microbiol Infect Dis. 2004;50(1):59-69. doi:10.1016/j.diagmicrobio.2004.05.003

11. Logan LK, Braykov NP, Weinstein RA, Laxminarayan R. Program CDCEP: extended-Spectrum beta-Lactamase-Producing and ThirdGeneration Cephalosporin-Resistant Enterobacteriaceae in Children: trends in the United States, 1999-2011. J Pediatric Infect Dis Soc. 2014;3(4):320-328. doi:10.1093/jpids/piu010

12. Flokas ME, Karanika S, Alevizakos M, Mylonakis E. Prevalence of ESBL-producing enterobacteriaceae in pediatric bloodstream infections: a systematic review and meta-analysis. PLoS One. 2017;12(1):e0171216. doi:10.1371/journal.pone.0171216

13. Bassetti M, Carnelutti A, Peghin M. Patient specific risk stratification for antimicrobial resistance and possible treatment strategies in gram-negative bacterial infections. Expert Rev Anti Infect Ther. 2017;15(1):55-65. doi:10.1080/14787210.2017.1251840

14. Goodman KE, Lessler J, Cosgrove SE, et al. Antibacterial resistance leadership G: a clinical decision tree to predict whether a bacteremic patient is infected with an extended-spectrum beta-lactamase-producing organism. Clin Infect Dis. 2016;63 (7):896-903. doi:10.1093/cid/ciw425

15. Sick-Samuels AC, Goodman KE, Rapsinski G, et al. A decision tree using patient characteristics to predict resistance to commonly used broad-spectrum antibiotics in children with gram-negative bloodstream infections. J Pediatric Infect Dis Soc. 2019;9(2):142-149.

16. Logan LK. Carbapenem-resistant enterobacteriaceae: an emerging problem in children. Clin Infect Dis. 2012;55(6):852-859. doi: $10.1093 / \mathrm{cid} / \mathrm{cis} 543$

17. Chiotos K, Han JH, Tamma PD. Carbapenem-Resistant Enterobacteriaceae Infections in Children. Curr Infect Dis Rep. 2016;18(1):2. doi:10.1007/s11908-015-0510-9

18. Logan LK, Renschler JP, Gandra S, Weinstein RA, Laxminarayan R. Centers for disease c, prevention epicenters $\mathrm{p}$ : carbapenem-resistant enterobacteriaceae in children, United States, 1999-2012. Emerg Infect Dis. 2015;21(11):2014-2021. doi:10.3201/eid2111.150548

19. Kehl SC, Dowzicky MJ. Global assessment of antimicrobial susceptibility among Gram-negative organisms collected from pediatric patients between 2004 and 2012: results from the Tigecycline Evaluation and Surveillance Trial. J Clin Microbiol. 2015;53(4):1286-1293. doi:10.1128/JCM.03184-14

20. Chiotos K, Tamma PD, Flett KB, et al. Multicenter study of the risk factors for colonization or infection with carbapenem-resistant enterobacteriaceae in children. Antimicrob Agents Chemother. 2017;61(12). doi:10.1128/AAC.01440-17

21. Folgori L, Bielicki J, Heath PT, Sharland M. Antimicrobialresistant Gram-negative infections in neonates: burden of disease and challenges in treatment. Curr Opin Infect Dis. 2017;30 (3):281-288. doi:10.1097/QCO.0000000000000371

22. Rutter WC, Burgess DR, Burgess DS. Increasing incidence of multidrug resistance among cystic fibrosis respiratory bacterial isolates. Microb Drug Resist. 2017;23(1):51-55. doi:10.1089/ mdr.2016.0048

23. Logan LK, Gandra S, Mandal S, et al. Prevention epicenters program uscfdc, prevention: multidrug- and carbapenemresistant pseudomonas aeruginosa in children, United States, 1999-2012. J Pediatric Infect Dis Soc. 2017;6(4):352-359. doi:10.1093/jpids/piw064

24. Keepers TR, Gomez M, Celeri C, Nichols WW, Krause KM. Bactericidal activity, absence of serum effect, and time-kill kinetics of ceftazidime-avibactam against beta-lactamase-producing Enterobacteriaceae and Pseudomonas aeruginosa. Antimicrob Agents Chemother. 2014;58(9):5297-5305. doi:10.1128/AAC.02894-14
25. Temkin E, Torre-Cisneros J, Beovic B, et al. Ceftazidimeavibactam as salvage therapy for infections caused by carbapenem-resistant organisms. Antimicrob Agents Chemother. 2017;61(2). doi:10.1128/AAC.01964-16

26. Humphries RM, Hindler JA, Wong-Beringer A, Miller SA. Activity of ceftolozane-tazobactam and ceftazidime-avibactam against beta-lactam-resistant pseudomonas aeruginosa isolates. Antimicrob Agents Chemother. 2017;61(12). doi:10.1128/AAC.01858-17

27. Karlowsky JA, Kazmierczak KM, Bouchillon SK, de Jonge BLM, Stone GG, Sahm DF. In vitro activity of ceftazidime-avibactam against clinical isolates of enterobacteriaceae and pseudomonas aeruginosa collected in latin American countries: results from the INFORM global surveillance program, 2012 to 2015. Antimicrob Agents Chemother. 2019;63(4). doi:10.1128/AAC.01814-18

28. Bassetti M, Vena A, Castaldo N, Righi E, Peghin M. New antibiotics for ventilator-associated pneumonia. Curr Opin Infect Dis. 2018;31(2):177-186. doi:10.1097/QCO.0000000000000438

29. Singh R, Kim A, Tanudra MA, et al. Pharmacokinetics/pharmacodynamics of a beta-lactam and beta-lactamase inhibitor combination: a novel approach for aztreonam/avibactam. $J$ Antimicrob Chemother. 2015;70(9):2618-2626. doi:10.1093/jac/dkv132

30. Hobson CA, Bonacorsi S, Fahd M, et al. Successful treatment of bacteremia due to NDM-1-producing Morganella morganii with aztreonam and ceftazidime-avibactam combination in a pediatric patient with hematologic malignancy. Antimicrob Agents Chemother. 2019;63(2). doi:10.1128/AAC.00779-19

31. Deshpande D, Srivastava S, Chapagain M, et al. Ceftazidimeavibactam has potent sterilizing activity against highly drug-resistant tuberculosis. Sci Adv. 2017;3(8):e1701102. doi:10.1126/sciadv. 1701102

32. Deshpande D, Srivastava S, Chapagain ML, et al. The discovery of ceftazidime/avibactam as an anti-Mycobacterium avium agent. J Antimicrob Chemother. 2017;72(suppl_2):i36-i42. doi:10.1093/ jac/dkx306

33. Shields RK, Chen L, Cheng S, et al. Emergence of Ceftazidime-avibactam resistance due to plasmid-borne blakpc-3 mutations during treatment of carbapenem-resistant klebsiella pneumoniae infections. Antimicrob Agents Chemother. 2017;61(3):e02097.

34. Tamma PD, Fan Y, Bergman Y, et al. Successful Treatment of Persistent Burkholderia cepacia Complex Bacteremia with Ceftazidime-Avibactam. Antimicrob Agents Chemother. 2018;62 (4):e02213-e02217. doi:10.1128/AAC.02213-17

35. European Union Clinical Trials Register [homepage on the Internet]. Amsterdam: European Medicines Agency (EMA). Available from: https://www.clinicaltrialsregister.eu. Accessed May 31, 2020.

36. ClinicalTrial.gov [homepage on the Internet]. Bethesda: National Institutes of Health. Available from: https://clinicaltrials.gov. Accessed May 31, 2020.

37. AstraZeneca AB. A Phase I Study to Assess the Pharmacokinetics, Safety and Tolerability of a Single Dose of Ceftazidime Avibactam (CAZ AVI) in Children From 3 Months of Age to $<18$ Years Who Are Receiving Systemic Antibiotic Therapy for Suspected or Confirmed Infection. Available from: https://www.clinicaltrialsregister.eu/ctr-search/trial/2013-00190013/results. EudraCT number: 2013-001900-13. Accessed May 31, 2020.

38. Pfizer. A Phase I Study to Assess the Pharmacokinetics, Safety and Tolerability of a Single Dose of Ceftazidime-Avibactam (CAZ-AVI) in Children From 3 Months of Age to $<18$ Years Who Are Receiving Systemic Antibiotic Therapy for Suspected or Confirmed Infection. Available from: https://clinicaltrials.gov/ ct2/show/NCT01893346. NLM identifier: NCT01893346. Accessed May 31, 2020. 
39. Bradley JS, Armstrong J, Arrieta A, et al. Phase I study assessing the pharmacokinetic profile, safety, and tolerability of a single dose of ceftazidime-avibactam in hospitalized pediatric patients. Antimicrob Agents Chemother. 2016;60(10):6252-6259. doi:10.1128/AAC.00862-16

40. Pfizer. A Phase I, Open-Label, Single-dose Study to Assess the Pharmacokinetics, Safety and Tolerability of CeftazidimeAvibactam (CAZ-AVI) in Children From 3 Months to Less than 18 Years of Age Who Are Hospitalized and Receiving Systemic Antibiotic Therapy for Suspected or Confirmed Nosocomial Pneumonia, Including Ventilator Associated Pneumonia. Avaible from: https://clinicaltrials.gov/ct2/show/NCT04040621. NLM identifier: NCT04040621. Accessed May 31, 2020.

41. Pfizer. A single blind, randomised, multi-centre, active controlled, trial to evaluate safety, tolerability, pharmacokinetics and efficacy of ceftazidime and avibactam compared with cefepime in children from 3 months to less than 18 years of age with complicated urinary tract infections (cUTIs). Avaible from: https://www.clin icaltrialsregister.eu/ctr-search/trial/2014-003244-13/PL. EudraCT number: 2014-003244-13. Accessed May 31, 2020.

42. Pfizer. Evaluation of Safety, Pharmacokinetics and Efficacy of Ceftazidime and Avibactam (CAZ-AVI) Compared With Cefepime in Children From 3 Months to Less Than 18 Years of Age With Complicated Urinary Tract Infections (cUTIs). Avaible from: https:/clinicaltrials.gov/ct2/show/NCT02497781. NLM identifier: NCT02497781. Accessed May 31, 2020.

43. Pfizer. A single blind, randomised, multi-centre, active controlled, trial to evaluate safety, tolerability, pharmacokinetics and efficacy of ceftazidime and avibactam when given in combination with metronidazole, compared with meropenem, in children from 3 months to less than 18 years of age with complicated intraabdominal infections (cIAIs). Avaible from: https://www.clinical trialsregister.eu/ctr-search/trial/2014-003242-28/GR. EudraCT number: 2014-003242-28. Accessed May 31, 2020.

44. Bradley JS, Roilides E, Broadhurst H, et al. Safety and Efficacy of Ceftazidime-Avibactam in the Treatment of Children $>/=3$ Months to $<18$ Years With Complicated Urinary Tract Infection: Results from a Phase 2 Randomized, Controlled Trial. Pediatr Infect Dis J. 2019;38 (9):920-928. doi:10.1097/INF.0000000000002395

45. Bradley JS, Broadhurst H, Cheng K, et al. Safety and Efficacy of Ceftazidime-Avibactam Plus Metronidazole in the Treatment of Children $>/=3$ Months to $<18$ Years With Complicated IntraAbdominal Infection: Results From a Phase 2, Randomized, Controlled Trial. Pediatr Infect Dis J. 2019;38(8):816-824. doi:10.1097/INF.0000000000002392

46. Esposito P, Sbrana F, Di Toro A, Gombos S, Tascini C. Ceftazidimeavibactam salvage therapy in newborn with KPC-producing Klebsiella pneumoniae invasive infections. Minerva Anestesiol. 2019;85(7):804-805. doi:10.23736/S0375-9393.19.13521-3

47. Algwizani A, Alzunitan M, Alharbi A, et al. Experience with ceftazidime-avibactam treatment in a tertiary care center in Saudi Arabia. J Infect Public Health. 2018;11(6):793-795. doi:10.1016/j. jiph.2018.04.013

48. Mosley JF, Smith LL, Parke CK, Brown JA, Wilson AL, Gibbs LV. Ceftazidime-avibactam (Avycaz): for the treatment of complicated intra-abdominal and urinary tract infections. P T peer-Rev J Formulary Manage. 2016;41(8):479-483.

49. Vardakas KZ, Voulgaris GL, Maliaros A, Samonis G, Falagas ME. Prolonged versus short-term intravenous infusion of antipseudomonal beta-lactams for patients with sepsis: a systematic review and meta-analysis of randomised trials. Lancet Infect Dis. 2018;18 (1):108-120. doi:10.1016/S1473-3099(17)30615-1

50. Shields RK, Potoski BA, Haidar G, et al. Clinical outcomes, drug toxicity, and emergence of ceftazidime-avibactam resistance among patients treated for carbapenem-resistant enterobacteriaceae infections. Clin Infect Dis. 2016;63(12):1615-1618. doi:10.1093/cid/ ciw636
51. Aitken SL, Tarrand JJ, Deshpande LM, et al. High rates of nonsusceptibility to ceftazidime-avibactam and identification of new delhi metallo-beta-lactamase production in enterobacteriaceae bloodstream infections at a major cancer center. Clin Infect Dis. 2016;63(7):954-958. doi:10.1093/cid/ciw398

52. Gaibani P, Campoli $\mathrm{C}$, Lewis RE, et al. In vivo evolution of resistant subpopulations of KPC-producing Klebsiella pneumoniae during ceftazidime/avibactam treatment. $J$ Antimicrob Chemother. 2018;73(6):1525-1529. doi:10.1093/jac/dky082

53. Sibley D, Simar S, Ashcraft D, Pankey G. In Vitro synergy of ceftazidime-avibactam plus rifampin against pseudomonas aeruginosa. Open Forum Infect Dis. 2016;3(suppl 1). doi:10.1093/ofid/ofw172.1568

54. Winkler ML, Papp-Wallace KM, Hujer AM, et al. Unexpected Challenges in Treating Multidrug-Resistant Gram-Negative Bacteria: Resistance to Ceftazidime-Avibactam in Archived Isolates of $<$ span class="named-content genus-species" id="namedcontent-1" $>$ Pseudomonas aeruginosa $</$ span $>$. Antimicrob Agents Chemother. 2015;59(2):1020-1029. doi:10.1128/AAC.04238-14

55. Papp-Wallace KM, Zeiser ET, Becka SA, et al. CeftazidimeAvibactam in combination with fosfomycin: a novel therapeutic strategy against multidrug-resistant pseudomonas aeruginosa. J Infect Dis. 2019;220(4):666-676. doi:10.1093/infdis/jiz149

56. Gaibani $\mathrm{P}$, Lewis RE, Volpe SL, et al. In vitro interaction of ceftazidime-avibactam in combination with different antimicrobials against KPC-producing Klebsiella pneumoniae clinical isolates. Int J Infect Dis. 2017;65:1-3. doi:10.1016/j.ijid.2017. 09.017

57. Gaudereto JJ, Perdigao Neto LV, Leite GC, et al. Synergistic effect of ceftazidime-avibactam with meropenem against panresistant, carbapenemase-harboring acinetobacter baumannii and serratia marcescens investigated using time-kill and disk approximation assays. Antimicrob Agents Chemother. 2019;63(5). doi:10.1128/AAC.02367-18

58. Jayol A, Nordmann P, Poirel L, Dubois V. Ceftazidime/avibactam alone or in combination with aztreonam against colistin-resistant and carbapenemase-producing Klebsiella pneumoniae. J Antimicrob Chemother. 2017;73(2):542-544. doi:10.1093/jac/dkx393

59. Barlow G, Morice A. Successful treatment of resistant Burkholderia multivorans infection in a patient with cystic fibrosis using ceftazidime/avibactam plus aztreonam. J Antimicrob Chemother. 2018;73(8):2270-2271. doi:10.1093/jac/dky136

60. Caston JJ, Lacort-Peralta I, Martin-Davila P, et al. Clinical efficacy of ceftazidime/avibactam versus other active agents for the treatment of bacteremia due to carbapenemase-producing Enterobacteriaceae in hematologic patients. Int $J$ Infect Dis. 2017;59:118-123. doi:10.1016/j.ijid.2017.03.021

61. Wilson APR. Sparing carbapenem usage. $J$ Antimicrob Chemother. 2017;72(9):2410-2417. doi:10.1093/jac/dkx181

62. Baquero-Artigao F, Del Rosal Rabes T. Fosfomycin in the pediatric setting: evidence and potential indications. Rev esp de quimioterapia. 2019;32(Suppl 1):55-61.

63. NCT03978091.

64. Li G, Standing JF, Bielicki J, et al. The potential role of fosfomycin in neonatal sepsis caused by multidrug-resistant bacteria. Drugs. 2017;77(9):941-950. doi:10.1007/s40265-017-0745-x

65. Iarikov D, Wassel R, Farley J, Nambiar S. Adverse events associated with fosfomycin use: review of the literature and analyses of the FDA adverse event reporting system database. Infect Dis Ther. 2015;4(4):433-458. doi:10.1007/s40121-015-0092-8

66. Traunmuller F, Popovic M, Konz KH, Vavken P, Leithner A, Joukhadar C. A reappraisal of current dosing strategies for intravenous fosfomycin in children and neonates. Clin Pharmacokinet. 2011;50(8):493-503. doi:10.2165/11592670000000000-00000 
67. Oteo J, Bautista V, Lara N, et al. Parallel increase in community use of fosfomycin and resistance to fosfomycin in extended-spectrum beta-lactamase (ESBL)-producing Escherichia coli. J Antimicrob Chemother. 2010;65(11):2459-2463. doi:10.1093/jac/dkq346

68. Durante-Mangoni E, Andini R, Zampino R. Management of carbapenem-resistant Enterobacteriaceae infections. Clin Microbiol Infect. 2019;25(8):943-950. doi:10.1016/j.cmi.2019.04.013

69. Nation RL. Dose suggestions for intravenous colistin in pediatric patients: caution required. Clin Infect Dis. 2018;66(5):810-811. doi:10.1093/cid/cix1048

70. Nation RL, Garonzik SM, Thamlikitkul V, et al. Dosing guidance for intravenous colistin in critically-ill patients. Clin Infect Dis. 2017;64(5):565-571. doi:10.1093/cid/ciw839

71. Antachopoulos C, Karvanen M, Iosifidis E, et al. Serum and cerebrospinal fluid levels of colistin in pediatric patients. Antimicrob Agents Chemother. 2010;54(9):3985-3987. doi:10.11 28/AAC.01799-09

72. Nakwan N, Usaha S, Chokephaibulkit K, Villani P, Regazzi M, Imberti R. Pharmacokinetics of colistin following a single dose of intravenous colistimethate sodium in critically ill neonates. Pediatr Infect Dis J. 2016;35(11):1211-1214. doi:10.1097/ INF.0000000000001263

73. Iosifidis E, Antachopoulos C, Ioannidou M, et al. Colistin administration to pediatric and neonatal patients. Eur J Pediatr. 2010;169(7):867-874. doi:10.1007/s00431-009-1137-3

74. Barco S, Castagnola E, Mesini A, Tripodi G, Cangemi G. Potential pitfalls in LC-MS/MS quantification of colistin for therapeutic drug monitoring of patients treated with colistimethate. J Pharm Biomed Anal. 2019;170:193-195. doi:10. 1016/j.jpba.2019.03.023

75. Mesini A, Loy A, Gattorno $\mathrm{M}$, et al. Colistin area under the time-concentration in children treated with intravenous loading dose and maintenance therapy. Clin Infect Dis. 2018;66 (5):808-809. doi:10.1093/cid/cix757

76. Iosifidis E, Violaki A, Michalopoulou E, et al. Use of tigecycline in pediatric patients with infections predominantly due to extensively drug-resistant gram-negative bacteria. $J$ Pediatric Infect Dis Soc. 2017;6(2):123-128. doi:10.1093/jpids/piw009

77. Purdy J, Jouve S, Yan JL, et al. Pharmacokinetics and safety profile of tigecycline in children aged 8 to 11 years with selected serious infections: a multicenter, open-label, ascending-dose study. Clin Ther. 2012;34(2):496-507.e491. doi:10.1016/j. clinthera.2011.12.010

78. Gustinetti G, Cangemi G, Bandettini R, Castagnola E. Pharmacokinetic/pharmacodynamic parameters for treatment optimization of infection due to antibiotic resistant bacteria: a summary for practical purposes in children and adults. J Chemother. 2018;30 (2):65-81. doi:10.1080/1120009X.2017.1377909

79. Zavascki AP, Bulitta JB, Landersdorfer CB. Combination therapy for carbapenem-resistant Gram-negative bacteria. Expert Rev Anti Infect Ther. 2013;11(12):1333-1353. doi:10.1586/14787210.20 13.845523

80. Mastrolia MV, Galli L, De Martino M, Chiappini E. Use of tigecycline in pediatric clinical practice. Expert Rev Anti Infect Ther. 2017;15(6):605-612. doi:10.1080/14787210.2017.1318064

81. McCracken GH. Aminoglycoside toxicity in infants and children. Am J Med. 1986;80(6, Supplement 2):172-178. doi:10.1016/ 0002-9343(86)90497-3

82. Castagnola E, Dallorso S, Haupt R. Administration schedule and ototoxicity of amikacin in children with cancer. Pediatr Blood Cancer. 2014;61(2):192. doi:10.1002/pbc.24740

83. Alqahtani S, Abouelkheir M, Alsultan A, et al. Optimizing amikacin dosage in pediatrics based on population pharmacokinetic/ pharmacodynamic modeling. Pediatric Drugs. 2018;20 (3):265-272. doi:10.1007/s40272-018-0288-y
84. Fisman DN, Kaye KM. Once-daily dosing of aminoglycoside antibiotics. Infect Dis Clin North Am. 2000;14(2):475-487. doi:10.1016/S0891-5520(05)70259-2

85. Hirai J, Hagihara M, Kato H, et al. Investigation on rifampicin administration from the standpoint of pharmacokinetics/pharmacodynamics in a neutropenic murine thigh infection model. J Infect Chemother. 2016;22(6):387-394. doi:10.1016/j.jiac.2016.02.011

86. Sendi P, Zimmerli W. The use of rifampin in staphylococcal orthopaedic-device-related infections. Clin Microbiol Infect. 2017;23(6):349-350. doi:10.1016/j.cmi.2016.10.002

87. Shabaan AE, Nour I, Elsayed Eldegla H, Nasef N, Shouman B, Abdel-Hady H. Conventional Versus Prolonged Infusion of Meropenem in Neonates With Gram-negative Late-onset Sepsis: A Randomized Controlled Trial. Pediatr Infect Dis J. 2017;36 (4):358-363. doi:10.1097/INF.0000000000001445

88. Lorente L, Lorenzo L, Martín MM, Jiménez A, Mora ML. Meropenem by continuous versus intermittent infusion in ventilator-associated pneumonia due to gram-negative bacilli. Ann Pharmacother. 2006;40(2):219-223. doi:10.1345/aph.1G467

89. Yu Z, Pang X, Wu X, Shan C, Jiang S. Clinical outcomes of prolonged infusion (extended infusion or continuous infusion) versus intermittent bolus of meropenem in severe infection: A meta-analysis. PLoS One. 2018;13(7):e0201667. doi:10.1371/ journal.pone.0201667

90. Abdul-Aziz MH, Lipman J, Akova M, et al. Is prolonged infusion of piperacillin/tazobactam and meropenem in critically ill patients associated with improved pharmacokinetic/pharmacodynamic and patient outcomes? An observation from the Defining Antibiotic Levels in Intensive care unit patients (DALI) cohort. $J$ Antimicrob Chemother. 2016;71(1):196-207. doi:10.1093/jac/dkv288

91. Cies JJ, Moore WS, Enache A, Chopra A. Population Pharmacokinetics and Pharmacodynamic Target Attainment of Meropenem in Critically Ill Young Children. $J$ Pediatr Pharmacol Ther. 2017;22(4):276-285. doi:10.5863/1551-677622.4.276

92. Pettit RS, Neu N, Cies JJ, et al. Population pharmacokinetics of meropenem administered as a prolonged infusion in children with cystic fibrosis. J Antimicrob Chemother. 2016;71(1):189-195. doi:10.1093/jac/dkv289

93. Norrby SR. Neurotoxicity of carbapenem antibiotics: consequences for their use in bacterial meningitis. $J$ Antimicrob Chemother. 2000;45(1):5-7. doi:10.1093/jac/45.1.5

94. Mesini A, Loy A, Losurdo G, et al. Uncommon occurrence of high piperacillin-tazobactam and meropenem plasma concentrations and concomitant absence of neurotoxicity in pediatrics. Minerva Anestesiol. 2018;84(9):1111-1112. doi:10.23736/S03759393.18.12600-9

95. Barco S, Bandettini R, Maffia A, et al. Quantification of piperacillin, tazobactam, meropenem, ceftazidime, and linezolid in human plasma by liquid chromatography/tandem mass spectrometry. J Chemother. 2015;27(6):343-347. doi:10.1179/ 1973947814Y.0000000209

96. Barco S, Castagnola E, Moscatelli A, Rudge J, Tripodi G, Cangemi G. Volumetric adsorptive microsampling-liquid chromatography tandem mass spectrometry assay for the simultaneous quantification of four antibiotics in human blood: method development, validation and comparison with dried blood spot. $J$ Pharm Biomed Anal. 2017;145:704-710. doi:10.1016/j.jpba.2017.07.033

97. Barco S, Risso FM, Bruschettini M, et al. A validated LC-MS/MS method for the quantification of piperacillin/tazobactam on dried blood spot. Bioanalysis. 2014;6(21):2795-2802. doi:10.4155/bio.14.205

98. Cangemi G, Barco S, Castagnola E, Tripodi G, Favata F, D'Avolio A. Development and validation of UHPLC-MS/MS methods for the quantification of colistin in plasma and dried plasma spots. J Pharm Biomed Anal. 2016;129::551-557. doi:10.1016/j.jpba.2016.08.002 
99. Solomkin JS, Mazuski JE, Bradley JS, et al. Diagnosis and management of complicated intra-abdominal infection in adults and children: guidelines by the surgical infection society and the infectious diseases society of America. Clin Infect Dis. 2010;50 (2):133-164. doi:10.1086/649554

100. Zobell JT, Young DC, Waters CD, et al. Optimization of anti-pseudomonal antibiotics for cystic fibrosis pulmonary exacerbations: I. aztreonam and carbapenems. Pediatr Pulmonol. 2012;47(12):1147-1158. doi:10.1002/ppul.22655
101. WHO: 21st Expert Committee on the Selection and Use of Essential Medicines [homepage on the Internet]. Geneva:World Health Organization. Available from: https:/www.who.int/selec tion_medicines/committees/expert/21/en. Accessed May 31, 2020.

102. Tygacil ${ }^{\circledR}$ (tygeciclin) (powder for infusion) [prescribing information]. European Medicines Agency; 2018.

\section{Publish your work in this journal}

Infection and Drug Resistance is an international, peer-reviewed openaccess journal that focuses on the optimal treatment of infection (bacterial, fungal and viral) and the development and institution of preventive strategies to minimize the development and spread of resistance. The journal is specifically concerned with the epidemiology of

Submit your manuscript here: https://www.dovepress.com/infection-and-drug-resistance-journa antibiotic resistance and the mechanisms of resistance development and diffusion in both hospitals and the community. The manuscript management system is completely online and includes a very quick and fair peerreview system, which is all easy to use. Visit http://www.dovepress.com/ testimonials.php to read real quotes from published authors. 